\title{
A morfologia prosódica e o comportamento transderivacional \\ da hipocorização no português brasileiro
}

\author{
Carlos Alexandre Gonçalves \\ Universidade Federal do Rio de Janeiro/CNPq
}

\section{Abstract}

In this paper, I analyse Brazilian Portuguese Hypocorization, in light of the Prosodic Morphology model proposed by McCarthy \& Prince (1990 and 1993). Agglutinative approaches refer to this phenomenon as idiosyncratic, unpredictible and awkward, considering that the process deletes sound sequences of anthroponims. Based on Prosodic Morphology, I argue against this hypothesis, showing that the process is highly regular if we consider (i) prosodic primitives and (ii) aspects of the phonology-morphology interface in Portuguese. By analyzing the phenomenon as a nonconcatenative one, I claim that Hypocorization does not delete sound sequences of the base. Instead it is characterized by melodic segment mapping of the first name onto a definite prosodic template. 


\section{PALAVRAS INICIAIS}

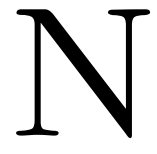

este artigo, analiso a formação de hipocorísticos no português do Brasil à luz do modelo de Morfologia Prosódica proposto por McCARTHY (1986) e posteriormente refinado por MCCARTHY \& PRINCE (1990 e 1993). Entendo por hipocorização o processo morfológico pelo qual antropônimos são encurtados afetivamente, resultando numa forma diminuta que mantém identidade com o prenome ou com o sobrenome original (cf., p. ex., 'Reginaldo' > 'Naldo'; 'Isabel' > 'Bel' e 'Alexandre' > 'Xande'). ${ }^{1}$

Abordagens aglutinativas fazem referência ao fenômeno como "idiossincrático", "imprevisível", "assistemático" e "esdrúxulo" (cf., p. ex., CUNHA, 1975; MONTEIRO, 1987; ZANOTTO, 1989), assumindo que o processo opera com supressão de uma seqüência fônica do antropônimo (palavra-matriz). Com base na morfologia prosódica, procuro refutar essa hipótese, evidenciando que o processo se mostra altamente regular quando se levam em conta (i) primitivos prosódicos e (ii) aspectos da interface Morfologia-Fonologia.

Analisando a operação como não-concatenativa, defendo a idéia de que a hipocorização não envolve apagamento de seqüências fônicas da base, caracterizando-se, na verdade, por um mapeamento dos segmentos melódicos do prenome para um molde prosodicamente definido (MESTER, 1990). Dessa maneira, sugiro que a operação seja vista como não-linear e, por isso mesmo, na qualidade de processo "mal-comportado de formação de palavras" (SPENCER, 1991), encontra guarida em modelos morfológicos não-aglutinativos.

Assumindo que não há supressão de material fônico do input, mas cópia para um molde prosódico, a estrutura subjacente da hipocorização pode ser interpretada como subespecificada, 
codificando nada além de uma representação prosódica. ${ }^{2}$ Esse procedimento analítico, mostra RUSSEL (1997), possibilita resguardar a idéia de que entidades morfológicas possuem representações subjacentes: o processo de formação de hipocorísticos pode ser representado por um morfema circunscritivo (DE LACY, 1999), que engatilha cópia automática de segmentos da palavra-matriz.

Proponho, neste artigo, que o molde da hipocorização opera de duas maneiras, como estabelecido pela morfologia prosódica: (a) como um alvo para o qual segmentos melódicos são mapeados e (b) como um delimitador que efetivamente reduz a palavra-matriz para um tamanho prosódico definido. Ao mostrar que esses nomes encurtados são as menores formas derivadas da língua, proponho (i) que eles sejam analisados em termos de moricidade e (ii) que a hipocorização deva ser considerada fenômeno de minimalidade. Para tanto, argumento que o troqueu moraico é um dos elementos básicos do sistema fonológico do português, uma vez que condições de palavra mínima são refletidas na formação de hipocorísticos, que, como padrão default, escaneia segmentos do prenome para um molde trocaico quantitativo. Com isso, pretendo dar seqüência ao debate iniciado por BISOL (2000) sobre a importância do pé métrico na gramática fonológica da língua.

O texto se estrutura da seguinte maneira: na seção 1, apresento brevemente os aspectos da morfologia prosódica que se fizeram relevantes na análise do processo ora focalizado. Nas seções seguintes, proponho um molde default para a formação de hipocorísticos, revisitando as principais abordagens sobre o acento lexical em português. Na seção 4, mostro que as simplificações silábicas encontradas nos hipocorísticos levam à superficialização de formas não-marcadas (McCARTHY \& PRINCE, 1994), o que permite estabelecer um paralelo entre hipocorização e linguagem infantil. Por fim, na seção 5, sintetizo as principais conclusões do estudo, acenando para a possibilidade de o troqueu moraico ser o pé básico de nossa língua. 


\section{A MORFOLOGIA PROSÓDICA}

Desenvolvida a partir dos avanços da fonologia não-linear (décadas de 70 e 80), a morfologia prosódica (doravante MP) é um modelo teórico que tenta explicar a interação Morfologia-Fonologia nos sistemas gramaticais e, para isso, leva em conta o papel mediador da prosódia. De acordo com McCARTHY \& PRINCE (1990), os princípios da MP são os seguintes:

\section{(a) Hipótese Básica da MP:}

Moldes (templates) são definidos em termos de autênticas unidades da prosódia - mora $(\mu)$, sílaba $(\sigma)$, pé $(\Sigma)$ e palavra fonológica $(\omega)$ - e constituem afirmação geral a respeito da estrutura possível de determinados processos morfológicos (p. 98);

\section{(b) Condição de Satisfação ao Molde:}

Processos morfológicos satisfazem um molde específico, que pode ser determinado tanto por princípios universais da Prosódia, quanto por princípios de boa-formação de línguas individuais; $\mathrm{e}$

\section{(c) Circunscrição Prosódica:}

O domínio sobre o qual determinadas operações morfológicas se aplicam pode ser mapeado por primitivos prosódicos, da mesma forma que, na morfologia concatenativa, afixos se circunscrevem a domínios morfológicos como raiz, tema e radical.

Em linhas gerais, a MP hipotetiza que moldes e circunscrições são formulados em termos de vocabulário da prosódia, devendo, por isso, respeitar suas condições de boa-formação. O principal objetivo do modelo é definir o domínio de operações morfológicas não processadas por meio da adição de formativos, isto é, dos casos em que o morfema é interpretado, nos termos de Jensen (1991), não 
como "coisa", mas como "regra". Dentro desse enfoque teórico, ganharam tratamento original processos como a infixação (McCARTHY, 1986), a reduplicação (McCARTHY \& PRINCE, 1990), o truncamento (BENUA, 1995) e os blends lexicais (PIÑEROS, no prelo).

Sendo processual, mas assumindo explicitamente a rubrica "item-e-arranjo" (McCARTHY \& PRINCE, 1990), a MP reforça a idéia de uma morfologia baseada em morfemas. Nessa linha de investigação, processos não-concatenativos não necessariamente esvaziam a noção de morfema, que pode ser concebido simplesmente como uma circunscrição efetuada sobre bases. Analisando as representações morfológicas numa dimensão multilinear, a MP consegue formalizar a descontinuidade de operações não-aglutinativas: "itens" podem ser "arranjados" num espaço pluridimensional, levando em conta a integração de primitivos morfológicos com primitivos prosódicos.

A hipocorização dá mostras de que o português, apesar de ser uma língua de morfologia predominantemente aglutinativa, também faz uso do chamado morfema circunscritivo (DE LACY, 1999) ${ }^{3}$ - uma entidade morfológica inteiramente desprovida de conteúdo subjacente, cuja "corpulência" resulta da cópia da base e do tamanho de restrições sobre a forma prosódica. Vejamos, a seguir, como esse morfema se manifesta na formação de nomes como 'Chico', 'Tina' e 'Valdo', hipocorísticos de 'Francisco', 'Cristina' e 'Edivaldo', respectivamente.

\section{CONDIÇÕES DE MINIMALIDADE NO MOLDE DA HIPOCORIZAÇÃO}

Antes de propor que hipocorísticos são palavras mínimas em português, faz-se necessário tecer breves comentários sobre o tipo de pé tomado como básico na língua. Abordagens métricas sobre o acento primário têm se mostrado divergentes nesse aspecto: MASSINICAGLIARI (1995) considera ser esse pé o troqueu moraico; LEE (1995), ao contrário, sugere que o troqueu silábico prevalece nos 
verbos e o iambo, nos não-verbos; BISOL (2000), por sua vez, evidencia a importância do troqueu silábico em processos como redução vocálica e haplologia, sugerindo a abertura de um debate sobre a questão. Sem a intenção de resolver essa polêmica, mostro, a seguir, que o troqueu moraico tem papel de destaque em processos de minimização, sendo, por isso, extremamente relevante na morfologia portuguesa.

Tem sido aceito que pés trocaicos sensíveis à quantidade não podem ter mais de duas sílabas e não podem ter sílabas pesadas em posições fracas (HAYES, 1995 e McCARTHY, 1991, entre outros). O troqueu quantitativo é um tipo de pé que consiste de duas moras, compreendendo duas sílabas leves sucessivas ou uma única pesada, como se vê em (1) a seguir:

(1)

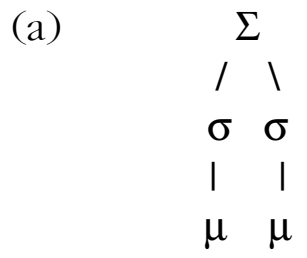

(b)

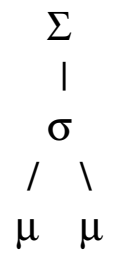

Para verificar se uma língua é sensível à quantidade, é necessário checar a atuação de fatores que determinam o peso das sílabas (HAYES, 1995). Alguns deles são universais; outros, no entanto, podem variar de uma língua para outra. Se uma sílaba CV é sempre leve (monomoraica) e uma sílaba CVV é sempre pesada (bimoraica), o mesmo não se pode dizer em relação a sílabas CVC. Para esse tipo de estrutura, HAYES (1995: 300) recomenda observar se a língua conta quantidade no núcleo ou na rima. Em (2), os parênteses em $(\boldsymbol{\mu})$ indicam que essa mora só é licenciada nas línguas em que a coda contribui para o peso das sílabas. 


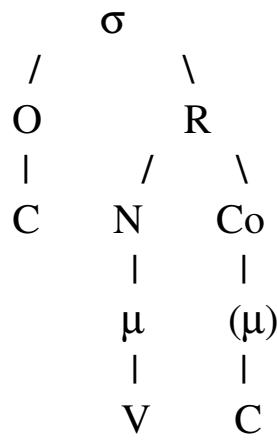

Em línguas que não distinguem vogais longas de breves, como é o caso do português, o peso silábico pode aparecer refletido na rima, caso seja atribuída uma mora à margem direita da sílaba, como em (2) sem os parênteses no segundo $\mu$. A oposição sílaba aberta $\mathrm{X}$ sílaba travada pode, portanto, encobrir diferenças de peso. Pares mínimos, como os abaixo listados (3), evidenciam que o acento tende a incidir na sílaba pesada final (BISOL, 1994), sendo sensível à presença de glide ou de consoante na margem direita da palavra. Esses dados sugerem que o português atribui duas moras à sílaba de rima ramificada e forma pés trocaico-moraicos pela borda direita da palavra. Nos exemplos, a sílaba tônica vem representada por um acento agudo sobre o núcleo (’).
(3) cóla/colár
pápa/papái
pásto/pastór máma/mamãe
lénço/lençól máma/mamão escála/escalár sóla/solár bébe/bebéu bólo/bolóu péle/peléi cáso/casóu

As regras do acento primário propostas por BISOL (1994) implicitamente fazem referência a uma contagem de moras: a regra de sensibilidade quantitativa parentetiza a sílaba final pesada e a regra de formação de constituintes prosódicos constrói um pé binário com dominância à esquerda, do tipo (* .), quando a última sílaba é leve. No primeiro caso, a ramificação da rima é computada como bimoraica, sendo formado um troqueu constituído de uma única 
sílaba pesada. No segundo, ao contrário, como a sîlaba final apresenta apenas uma mora, forma-se um pé dissilábico com cabeça inicial. Essas duas regras têm o formato de um troqueu moraico básico (cf. 4), como propõe HAYES (1995):

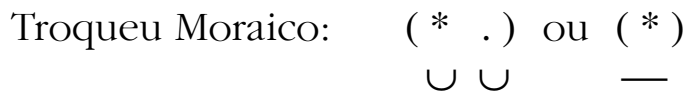

O acento lexical, no entanto, não é o único fato fonológico que levanta a suspeita de o troqueu moraico ser o pé básico do português. Domínios de aplicação de regras fornecem evidências mais fortes para decidir se um constituinte prosódico é funcionalmente relevante na língua (NESPOR \& VOGEL, 1986). O principal argumento para que se considere o pé trocaico-quantitativo como básico é sua relevância em processos de minimização prosódica (CABRÉ, 1994), a exemplo do que acontece na hipocorização. Feitas essas considerações, passemos à descrição do que vem a ser tomado como 'palavra mínima' no âmbito da Teoria Fonológica atual.

Na hierarquia prosódica (NESPOR \& VOGEL, 1986), o pé é o constituinte situado entre a sílaba e a palavra fonológica, como se vê em (5). Estaremos diante de uma palavra prosódica mínima todas as vezes em que $(\omega)$ dominar um e somente um $(\Sigma)$. Monossílabos com rima ramificada ('sol', 'céu' e 'mar') e dissílabos com sílaba final leve ('casa', 'pele' e 'bolo') são exemplos de palavras mínimas em português. No primeiro caso, as duas moras do troqueu se localizam numa única sílaba, como na representação (1b) acima, e, no segundo, as duas moras se distribuem por duas sílabas leves, como em (1a).

$$
\omega>\Sigma>\sigma>\mu
$$

Conforme mostra CABRÉ (1994: 2), línguas requerem condições de minimalidade na constituição de seu vocabulário. ${ }^{4}$ Essas condições, entretanto, também podem aparecer refletidas em 
processos morfológicos de encurtamento, como é o caso da reduplicação (McCARTHY \& PRINCE, 1995), do truncamento (BENUA, 1995) e, conseqüentemente, da hipocorização. Levando em conta que o pé básico do português é o troqueu moraico, hipocorísticos podem ser considerados as menores derivações da língua portuguesa. Condições de palavra mínima são impostas a esse tipo de formação, que escaneia material segmental da base para um molde trocaico moraico, bloqueando qualquer formação (a) maior que duas sílabas e (b) que não contenha pelo menos um pé trocaico, como detalharei a seguir.

\section{SISTEMAS DE HIPOCORIZAÇÃO EM PORTUGUÊS}

Para verificar os mecanismos ativados pela Hipocorização, foi mantida sob controle uma amostra constituída de 150 (cento e cinqüenta) antropônimos, selecionados em função de três variáveis, fundamentalmente: (a) tamanho (de dissílabos a polissílabos), (b) pauta acentual (oxítonas, paroxítonas e proparoxítonas) e (c) estrutura silábica (sílabas V, CV, CCV, CVC, CCVC e CCVCC). Um formulário com trinta nomes próprios foi apresentado a vinte colaboradores cariocas (dez homens e dez mulheres), de diferentes faixas etárias e níveis de escolarização. Com o objetivo de detectar possíveis padrões variáveis, uma mesma listagem foi apresentada a quatro informantes que foram instruídos a fornecer, para cada nome constante da lista, uma "forma mais afetiva, mais íntima e mais carinhosa de chamar pessoas que se chamam X". O exame dos formulários foi complementado com o dicionário de hipocorísticos elaborado por MONTEIRO (em preparação).

São quatro as estratégias de hipocorização encontradas no português brasileiro, especificamente na variedade carioca. Como outras línguas, o português pode recorrer a vários mecanismos para encurtar um nome próprio, a exemplo do que ocorre com 'Eduardo', que funciona como base para a criação de três hipocorísticos ('Dádo', 'Edú' e 'Dudú'). Os dados aparecem em (6) e devem ser lidos na 
vertical, uma vez que cada coluna exemplifica um diferente sistema de hipocorização.

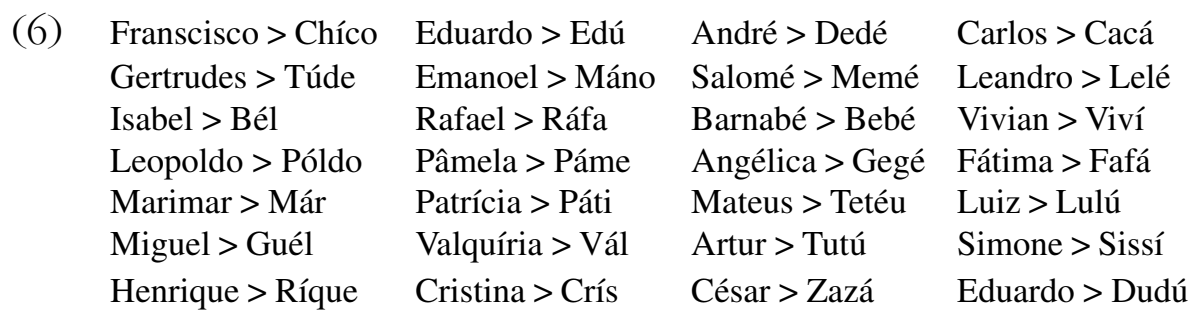

Apesar de diferentes em vários aspectos, os hipocorísticos nunca ultrapassam o limite de duas sílabas, embora a acentuada possa ser a primeira (colunas 1 e 2) ou a última (colunas 3 e 4). Como se vê, o parsing pode ser feito da direita para a esquerda (colunas 1 e 3) ou da esquerda para a direita (coluna 2 e 4). A hipocorização pode atuar sozinha (colunas 1 e 2) ou em conjunto com a Reduplicação (colunas 3 e 4). Do grupo “A” para o grupo "D”, há uma espécie de continuum de opacidade. Os dois primeiros são mais transparentes, pois, mais fiéis às bases, possibilitam rastrear o prenome sem grandes dificuldades. Os demais, ao contrário, tendem a ser mais opacos por permitirem que mais de uma palavra-matriz atue como base. É o caso de 'Jujú', que pode levar a qualquer antropônimo que se inicie por 'Ju', quer essa sílaba seja a tônica ('Júlia', 'Júnior'), quer não ('Jussara', 'Juliana'): não há fidelidade suficiente para que se evoque apenas um prenome.

Como o primeiro sistema caracterizou quase setenta por cento dos dados (Tabela 7), a hipocorização da coluna 1 - que passo a chamar de "Tipo A" - é a mais produtiva e pode ser considerada modelo geral para a formação de hipocorísticos em português, de modo que focalizarei, neste artigo, somente esse tipo de operação. ${ }^{5}$ 
(7)

\begin{tabular}{c|c|c|c|c}
\hline Tipo "A" & Tipo "B" & Tipo "C" & Tipo "D" & Outros $^{6}$ \\
\hline $96 / 150$ & $18 / 150$ & $21 / 150$ & $11 / 150$ & $4 / 150$ \\
$65,2 \%$ & $10,8 \%$ & $14,2 \%$ & $7,8 \%$ & $2 \%$ \\
\hline
\end{tabular}

A principal característica das formas reduzidas por meio da hipocorização do Tipo "A" é a manutenção do acento lexical das palavras-matrizes: a parte escaneada é justamente aquela que contém a sílaba proeminente, que não pode ser removida de sua posição original. Levando em conta a estrutura silábica, podemos distribuir esses hipocorísticos em três grupos, como se vê em (8) a seguir.

$\begin{array}{lll}\text { Felipe }>\text { Lípe } & \text { Raquel }>\text { Quél } & \text { Alexandre }>\text { Xánde } \\ \text { Antônio }>\text { Tónho } & \text { Isabel }>\text { Bél } & \text { Edivaldo }>\text { Váldo } \\ \text { Augusto }>\text { Gúto } & \text { Marimar }>\text { Már } & \text { Fernando }>\text { Nándo } \\ \text { Filomena }>\text { Ména } & \text { Nicolau }>\text { Láu } & \text { Reginaldo }>\text { Náldo } \\ \text { Roberto }>\text { Béto } & \text { Miguel }>\text { Guél } & \text { Rosimeire }>\text { Méire } \\ \text { Francisco }>\text { Chíco } & \text { Irineu }>\text { Néu } & \text { Leopoldo }>\text { Póldo } \\ \text { Marilena }>\text { Léna } & \text { Marissol }>\text { Sól } & \text { Gumercinda }>\text { Cínda }\end{array}$

O primeiro, mais produtivo que os demais, é exemplificado pelas formações da primeira coluna e apresenta estrutura 'CV.CV. O segundo, formado por monossílabos, compreende os nomes da coluna 2 e tem padrão silábico 'CVC. Nesse grupo, a palavra-matriz é oxítona e a sílaba final é travada por uma líquida ('Isabel') ou apresenta ditongo decrescente ('Nicolau'). O terceiro e último grupo (coluna 3), com estrutura 'CVC.CV, reúne hipocorísticos trocaicodissilábicos com a sílaba proeminente pesada. Apresento, a seguir, o mecanismo derivacional acionado por esse sistema de hipocorização.

O processo de formação de hipocorísticos do tipo "A" se inicia com a definição de um domínio sobre a base: a circunscrição prosódica delimita a porção da palavra-matriz sobre a qual a operação atuará. Dois parâmetros específicos regem a circunscrição - (a) o do pé e (b) o da direcionalidade (ver 9) -, definindo o que 
se chama de delimitação positiva (McCARTHY \& PRINCE, 1990). Todo o material remanescente, que constitui a circunscrição negativa, ainda de acordo com McCARTHY \& PRINCE (op. cit.), será desassociado por não estar licenciado prosodicamente. A circunscrição positiva atua no sentido de isolar uma palavra mínima, já que da direita para a esquerda é formado um troqueu moraico que será copiado do domínio-fonte (a palavra-matriz) para o domínio-alvo (o molde).

Parâmetro do pé:

Troqueu Moraico $([\mu \mu])$

Direcionalidade:

$\mathrm{E} \leftarrow \mathrm{D} \# \#$

"Forme um troqueu moraico pela borda direita da palavra-matriz"

A vogal tônica do pé mais à direita constituirá a primeira mora do troqueu. Havendo coda ou ditongo pesado (BISOL, 1989) na sílaba final, o troqueu será monossilábico, como em 'Bél' ('Isabel') e 'Néu' ('Irineu'). Se não houver ramificação no núcleo ou na rima da sílaba final, ao contrário, ter-se-á um troqueu dissilábico, como em 'Lipe' ('Felipe') e 'Xande' ('Alexandre'). Levando em conta a proposta do alinhamento generalizado (McCARTHY \& PRINCE, 1993), podemos dizer que os limites da circunscrição prosódica sempre coincidirão com os limites da sílaba, de modo que (i) onsets não podem desgarrar de suas rimas, (ii) núcleos ser apagados ou inseridos, (iii) nem codas podem ser ressilabificadas.

Em (10), aparece formalizado o procedimento da circunscrição prosódica. Tanto em 'Felipe' quanto em 'Isabel', a margem direita da base coincide com a margem direita da circurscrição prosódica e, conseqüentemente, com a margem direita do molde para a formação do hipocorístico. Da direita para a esquerda, forma-se um pé bimoraico que separa a seqüência da base a ser utilizada na hipocorização. O material silábico restante, que não será aproveitado (a sílaba 'Fe', de 'Felipe', e as sílabas 'I' e 'sa', de 'Isabel'), constitui a cirscunscrição negativa.' Confira-se (10): 
(10)

\begin{tabular}{|c|c|}
\hline$\Sigma$ & $\Sigma$ \\
\hline 11 & 11 \\
\hline $\begin{array}{ll}\mu & \mu\end{array}$ & $\mu \mu$ \\
\hline 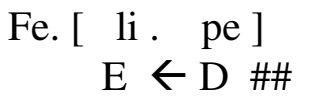 & $\begin{array}{r}\text { I. sa. }\left[\begin{array}{lll}b & \text { e } & 1\end{array}\right] \\
E \leftarrow D\end{array}$ \\
\hline
\end{tabular}

A morfologia prosódica assume que processos como esse não consistem de uma simples cópia de um constituinte obtido via circunscrição, mas de sua projeção para um molde CV (McCARTHY \& PRINCE, 1990). Dessa maneira, algumas condições prosódicas devem ser satisfeitas na projeção para o molde dos hipocorísticos. Chamemos o primeiro requisito de "condição de minimalidade":

(11) Condição de Minimalidade: A projeção para o molde CV contém um e somente um troqueu moraico.

A segunda condição, a de bissilabicidade, aparece como conseqüência da primeira, em função do parsing imposto pela formação do troqueu quantitativo. Pode ser formulada nos seguintes termos:

(12) Condição de Bissilabicidade: O molde do truncamento não pode consistir de mais de duas sílabas.

Essas duas condições explicam o estranhamento das formas abaixo (13), em que uma palavra com sílaba final leve serve de input ao processo: não é possível aplicar a circunscrição a estas bases, pois os hipocorísticos não funcionariam como palavras mínimas na língua (coluna 1). Outras estratégias - como a Reduplicação (coluna 2), o acréscimo de material fônico após a cópia da sílaba acentuada (coluna 3) e a formação de um troqueu à esquerda da base (coluna 4) - são utilizadas com o propósito de assegurar a formação do hipocorístico. Vejam-se os dados: 


\section{(13) André $>$ *Dé André $>$ Dedé André $>$ Déco

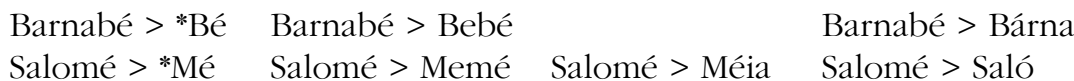 Dinorá $>$ *Rá Dinorá > Naná}

A hipocorização constitui contra-evidência à idéia de serem pesadas sílabas finais de oxítonas terminadas em vogal, como sugerem, entre outros, BISOL (1994) e MASSINI-CAGLIARI (1995). Na proposta de BISOL (op. cit.), palavras como 'café' e 'sofá' teriam, no nível subjacente, uma consoante abstrata que pode vir à superfície com o acréscimo de sufixos, como em 'cafezeiro' e 'sofazinho'. Dessa forma, a sílaba final de 'café' seria pesada por apresentar o formato CVC. Para MASSINI-CAGLIARI (op. cit.), ao contrário, as últimas vogais dessas oxítonas constituem núcleos de dois tempos (VV), o que torna as sílabas finais pesadas e, por isso, responsáveis pela formação de um troqueu quantitativo.

Se as sílabas finais de nomes como 'Salomé' e 'Barnabé' realmente fossem bimoraicas, não haveria bloqueio à formação de monossílabos sem coda. No entanto, formas como 'Mé' e 'Bé' não parecem bons hipocorísticos exatamente por violarem a condição de minimalidade. Salientei mais acima que hipocorísticos são outputs de um molde formado pela delimitação de um troqueu moraico à direita da palavra-matriz. A circunscrição prosódica, que parentetiza sílabas finais pesadas, não parece sensível à presença de uma consoante abstrata ou de uma vogal longa à direita de prenomes oxítonos, provavelmente por não encontrar, ali, as duas moras necessárias à formação de um troqueu. Como conseqüência, o modelo default (tipo "A") não pode ser acionado e, por isso, favorece o aparecimento de padrões variáveis (cf. colunas 2,3 e 4 de (13)). ${ }^{8}$

Oxítonas são bons inputs à formação de hipocorísticos do tipo "A", desde que apresentem ramificação no núcleo (ditongo decrescente) ou na rima (coda). Prenomes agudos com sílaba final leve, como 'Salomé' e 'Barnabé', não resultam em formas com padrão CV, de modo que monossílabos leves nunca são derivados pela hipocorização default. A circunscrição prosódica não pode ser processada pela 
impossibilidade de aplicação do parâmetro do pé: um troqueu quantitativo não pode ser representado por apenas uma mora. Oxítonas terminadas em vogal fornecem evidências fortes de que (i) a circunscrição prosódica realmente isola uma palavra mínima, (ii) o troqueu moraico é o pé básico do português brasileiro e (iii) são leves as sílabas finais de palavras como 'Sueli' e 'Dinorá'.

Nos prenomes proparoxítonos, a cópia do material da base poderia levar a um hipocorístico constituído de três sílabas (dados de (14), primeira coluna). Como a hipocorização necessariamente forma palavras mínimas, os dados abaixo violam a condição de bissilabicidade. Nesses casos, a última sílaba, considerada extramétrica para efeitos de atribuição de acento lexical (BISOL, 1994), parece ter efeito na formação do hipocorístico, uma vez que a vogal final é sistematicamente incorporada ao pé trocaico formado via circunscrição prosódica.
(14) Angélica > *Gélica
Débora $>$ Déba
Penélope $>$ *Nélope
Rômulo > Rômo
Américo $>$ *Mérico
Rosângela > Zánza
Rosângela $>$ *Zângela
Austregésilo > Géso
Eurípedes $>$ *Rípedes
Américo > Méco
Austregésilo $>$ *Gésilo
Eurípedes > Pípe (a partir de 'Pipinho)

Os dados de (14) fornecem evidência de que outra condição deve ser satisfeita na hipocorização. Baseado em McCARTHY \& PRINCE (1996), estou chamando esse requisito de Condição de Ancoragem à Direita que pode ser definida da seguinte maneira:

(15) Condição de Ancoragem à Direita: Elementos da periferia direita do prenome devem ter um correspondente na periferia direita do hipocorístico.

Na representação abaixo, exemplifico a formação de 'Déba', hipocorístico cuja base é 'Débora'. Uma vez processadas a silabação e a atribuição de acento lexical à primeira sílaba, em decorrência da 
extrametricalidade da última (BISOL, 1994), forma-se um troqueu moraico com a seqüência 'débo'. Embora atue em conformidade com as condições de minimalidade e bissilabicidade, esse pé não constitui bom hipocorístico em português exatamente porque não satisfaz a condição expressa em (15), por não preservar o segmento mais à direita da base. O hipocorístico 'Déba', portanto, emerge como forma ótima, satisfazendo os três requisitos impostos pela hipocorização.

(16)

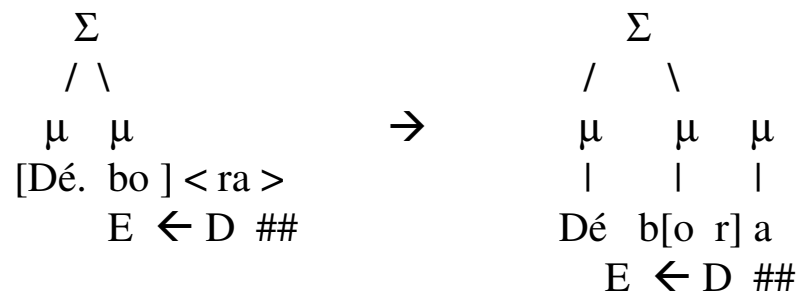

Voltemos aos exemplos apresentados em (8). Todas as palavras-matrizes da segunda coluna são nomes acentuados na sílaba pesada final. Significa dizer que um pé moraico foi construído nessa sílaba: as duas posições da rima preenchem as moras requeridas pelo troqueu. Então, 'Bel', de 'Isabel', e 'Neu', de 'Irineu', são bons hipocorísticos porque satisfazem a condição de minimalidade. Tendo apenas uma sílaba pesada, também satisfazem a condição de bissilabicidade, uma vez que tal condição faz exigência ao número máximo de sílabas. Os segmentos mais periféricos do prenome correspondem aos elementos finais do hipocorístico, de modo que a Condição de Ancoragem à Direita também é satisfeita.

Decorre, desse conjunto de condições, que nomes cujo tamanho coincida com o da circunscrição prosódica não se sujeitam à formação de hipocorísticos, pelo menos no formato aqui proposto. É impossível aplicar o molde a prenomes como 'Clara', 'Marta' ou 'Luís'. Nesses casos, ganham destaque processos como a Reduplicação ('Cacá', 'Tatá' e 'Lulú', respectivamente), pois o procedimento da circunscrição delimitaria toda a palavra. Como os hipocorísticos têm de ser necessariamente menores que os antropônimos corres- 
pondentes, o molde não se aplica, o que confirma serem essas formas a conseqüência pela busca da minimização.

Consideremos, por fim, os exemplos da terceira coluna de (8), repetidos em (17) por conveniência. Em todas as palavras-matrizes desse grupo, a penúltima sílaba, a que porta o acento, é pesada: o material contido em sua rima preenche as duas posições moraicas do troqueu. Dito de outra maneira, o troqueu moraico coincide com a sílaba proeminente da base. Mostrei, em (9), que o parâmetro do pé determina a margem esquerda da circunscrição prosódica e a direcionalidade do processo. A forma resultante, no entanto, não é exatamente uma palavra mínima, posto que não apresenta um pé bimoraico estrito.

$$
\begin{aligned}
& \text { Alexandre > Xánde } \\
& \text { Edivaldo > Váldo } \\
& \text { Fernando > Nándo } \\
& \text { Reginaldo > Náldo }
\end{aligned}
$$

Todos os dados de (17) têm a mesma forma pela circunscrição, embora sejam maiores que uma palavra mínima. Apesar disso, o molde da hipocorização satisfaz os três requisitos propostos, pois (a) apenas um troqueu moraico está incluído na circunscrição, (b) não há mais de duas sílabas no hipocorístico e (c) os segmentos periféricos da derivante aparecem no derivado. Como vimos, o processo atua no sentido de formar um troqueu moraico à direita do prenome. Sua última sílaba é monomoraica e, por isso, o processo de delimitação avança para a esquerda, buscando completar a segunda mora. Levando em conta que os limites da circunscrição sempre coincidem com os da sílaba, a margem esquerda da penúltima sílaba delimita o molde para a formação do hipocorístico. Como se vê em (18), a sílaba final leve é adjungida diretamente à palavra prosódica, satisfazendo a Condição de Bissilabicidade, e as duas moras da silaba pesada satisfazem a Condição de Minimalidade, fazendo com que uma palavra mínima esteja incluída no hipocorístico: 


$$
\begin{aligned}
& \omega \\
& \text { / I I } \\
& \mu \quad \mu \quad \mu
\end{aligned}
$$

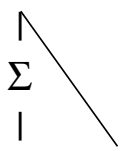

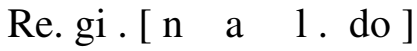

$$
\begin{aligned}
& \mathrm{E} \leftarrow \mathrm{D} \# \#
\end{aligned}
$$

Alguns exemplos de (8) mostram que pode haver diferenças entre o material escaneado pela circunscrição prosódica e o que efetivamente aparece nos hipocorísticos. Simplificações estruturais, como 'Beto', de 'Roberto' e 'Chico', de 'Francisco' podem ser entendidas como estratégias que fazem emergir formas nãomarcadas (McCARTHY \& PRINCE, 1994). Estruturas silábicas menos complexas constituem tendência na formação de hipocorísticos que privilegiam sílabas destravadas (BENUA, 1995; e COLINA, 1996), onsets simples (CABRÉ, 1994; e PIÑEROS, 2000), além de não se iniciarem por vogais (MESTER, 1990).

Sem dúvida alguma mais usado na formação de hipocorísticos, o padrão 'CV.CV' é, indiscutivelmente, uma estrutura não-marcada em português: um pé binário constituído de sílabas abertas com cabeça à esquerda. Dessa maneira, diferenças entre o conteúdo escaneado pela circunscrição prosódica e o que aparece nos hipocorísticos podem ser entendidas como resultantes do papel desempenhado pelas condições de boa-formação silábica sobre a porção da palavra-matriz que se projetou para o molde CV (McCARTHY \& PRINCE, 1990). Essas condições acabam sacrificando ainda mais a identidade prenome-hipocorístico, mas não atuam no input; agem sobre o material copiado via circunscrição, como no esquema a seguir. 


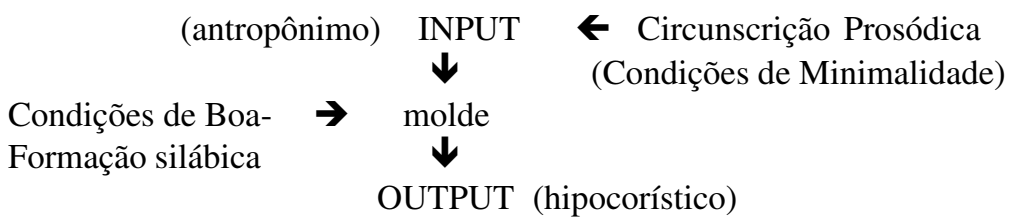

Como se vê em (19), há um nível de representação entre o input e o output, de modo que condições de minimalidade atuam no input (prenome), gerando um output (molde), que, por sua vez, passa a ser o input sobre o qual atuarão condições de boa-formação silábica. Uma vez satisfeitas, essas condições levarão ao hipocorístico (output final). O molde, portanto, é a forma gerada pela circunscrição, mas também a forma a ser regulada pelas condições de boaformação silábica.

Pela representação acima (cf. 19), somos forçados a interpretar o processo como transderivacional (McCARTHY \& PRINCE, 1990), uma vez que há necessidade de um nível intermediário entre base e produto. Passemos, então, ao mapeamento das condições que regulam o output final. Ao mesmo tempo em que garantem superficialização de estruturas não-marcadas, tais condições levam o hipocorístico a destoar do molde, em termos de correspondência de conteúdo segmental, como se vê nos exemplos abaixo.

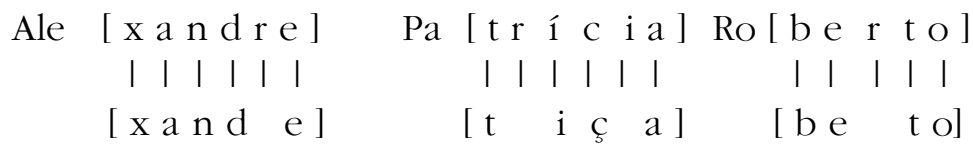

\section{DIFERENÇAS ENTRE HIPOCORÍSTICOS E MOLDES}

Iniciemos o levantamento das diferenças entre o conteúdo segmental mapeado pelas circunscrições e os hipocorísticos, focalizando o comportamento dos onsets. Dois aspectos podem ser levantados em relação ao grupo de dados apresentados em (21) a seguir. Em primeiro lugar, existem bases sem onsets na sílaba acentuada, e o hipocorístico preenche essa posição, copiando o 
ataque da sílaba final (coluna 1). Em segundo lugar, prenomes podem apresentar onsets complexos, mas os hipocorísticos correspondentes preservam apenas um segmento desse nó ramificante (coluna 2). Em todos os casos, o elemento que sobrevive à simplificação é sempre o de sonoridade mais baixa, de modo que seqüências CC são sempre desfeitas com o cancelamento de uma líquida.

$$
\begin{array}{ll}
\text { Eduardo }>\text { Dádo } & \text { Alexandre }>\text { Xánde } \\
\text { Mariana }>\text { Nána } & \text { Gertrudes }>\text { Túde } \\
\text { Joelma }>\text { Mélma } & \text { Euclides }>\text { Kíde }
\end{array}
$$

Os dados de (21) evidenciam que hipocorísticos requerem a presença de onsets ao mesmo tempo em que banem complexidade estrutural nesse constituinte. A hipocorização - entendida como processo morfológico que traz à tona estruturas não-marcadas - leva o padrão $\mathrm{CV}$ a emergir como formato básico dos itens derivados. Dessa maneira, a posição de onset deve ser preenchida a qualquer custo - e por um único segmento -, mesmo que, para isso, seja necessário sacrificar a relação de correspondência visualizada em (20).

A preservação de um obstruinte no ataque pode ser interpretada como conseqüência do Princípio de Sonoridade (CLEMENTS, 1990: 294), segundo o qual a curva de sonoridade deve aumentar maximamente na demissílaba inicial e cair minimamente na demissílaba final. Levando em conta a escala apresentada em (22), a combinação obstruinte-vogal (0-3) favorece maior elevação de sonoridade do onset para o pico silábico que a seqüência líquidavogal (2-3). Hipocorísticos tendem a conservar o primeiro elemento do grupo, otimizando a posição de onset através da seleção de segmentos mais harmônicos.

(22) Escala de sonoridade: Vogal > Líquida > Nasal > Obstruinte

$$
\begin{array}{llll}
3 & 2 & 1 & 0
\end{array}
$$

Uma interessante modificação fonológica aparece nos dados de (23), nos quais um tepe aparece como ataque inicial do pé 
formado durante a circunscrição prosódica. A impossibilidade de o português apresentar /r/ em início de palavras força a utilização de uma estratégia de reparo para substituir o segmento indevido e preencher essa posição. Como hipocorísticos tendem a banir sílabas sem onset, ${ }^{9}$ a melhor solução vem a ser copiar o ataque da sílaba seguinte, de modo a não sacrificar, ainda mais, a identidade prenome-hipocorístico.

$$
\begin{aligned}
& \text { Murilo }>\text { Lilo } \\
& \text { Nazareno }>\text { Neno } \\
& \text { Florinda }>\text { Dinda }
\end{aligned}
$$

Moldes com tepe à esquerda se comportam da mesma maneira que os não-iniciados por onset. Em ambos os casos, a consoante da sílaba final é copiada, a fim de preencher o ataque da primeira sílaba, o que prova, mais uma vez, que há condições de estrutura silábica governando o conteúdo segmental do hipocorístico.

A substituição do tepe é conseqüência do Princípio de Preservação de Estrutura (KIPARSKY, 1982), segundo o qual regras lexicais não podem operar com traços não-distintivos nem criar estruturas em desacordo com os padrões prosódicos básicos da língua. Por ser um processo morfológico (lexical), a hipocorização se sujeita à Preservação de Estrutura, reparando moldes com segmentos que não podem aparecer em início de palavras.

No que diz respeito ao onset, há, portanto, três condições (cf. 24) que regulam a configuração segmental do molde e levam ao output final (o hipocorístico propriamente dito):

(24) (a) a posição de ataque não pode ser vazia (*V);

(b) onsets complexos são sempre banidos (*CCV); e

(c) as sílabas iniciais dos hipocorísticos não podem apresentar um tepe $(* \#[r] \omega)$.

Estabelecidas essas condições sobre o onset, passemos a analisar, a seguir, os prenomes terminados em -ia e -io (cf. 25): 
(25)

$$
\begin{aligned}
& \text { Patrícia }>\text { Tíça } \\
& \text { Fabrício }>\text { Bíço }
\end{aligned}
$$

Seqüências [vogal alta-vogal] são sempre simplificadas e constituem problema na análise dos hipocorísticos. Com comportamento variável no português contemporâneo, esse tipo de estrutura pode ser realizado como hiato ('Pa-trí-ci-a') ou como ditongo crescente ('Pa-trí-cia'). Segundo BISOL (1989: 215), palavras como essas devem ser vistas como proparoxítonas terminadas em hiato, uma vez que ditongos crescentes são rimas de duas diferentes sílabas na estrutura subjacente. Dessa maneira, o ditongo resulta da ressilabificação, que faz com que a vogal alta se desligue da posição de núcleo para alojar-se no espaço de X disponível para aceitá-la, dando preferência ao da esquerda, em conformidade com o padrão silábico.

Para BISOL (1989), ditongos crescentes não fazem parte do inventário fonológico do português e surgem da fusão de duas rimas. Os argumentos apresentados pela autora são os seguintes: (a) seqüências glide-vogal estão normalmente em variação livre com o hiato, e (b) a semivogal dos ditongos crescentes nunca é apagada (p. 218). Se, por um lado, o hiato alterna com o ditongo crescente, por outro, a realização ditongada é, sem dúvida alguma, a mais usual (FAUSTO, 1998), pelo menos na variedade carioca. Em segundo lugar, o glide, de fato, nunca é cancelado em posição tônica. No entanto, quando átono e precedido de consoantes coronais, é grande a tendência ao apagamento da semivogal, como se observa nos dados de (26), extraídos de LEMLE (1978):

$$
\begin{aligned}
& \text { paciência } \sim \text { paciença } \\
& \text { delícia } \sim \text { deliça } \\
& \text { salário } \sim \text { salaro } \\
& \text { anúncio } \sim \text { anunço }
\end{aligned}
$$

No caso da hipocorização, é mais vantajoso interpretar 'Fabrício' e 'Patrícia' como paroxítonas terminadas em ditongo 
crescente. Algumas evidências reforçam esse ponto-de-vista. Em primeiro lugar, a porção da base utilizada na circunscrição é 'trícia' e 'brício'. Como vimos, a circunscrição prosódica sempre escaneia um troqueu moraico. É possível admitir que a vogal alta não foi computada como unidade moraica por fazer parte do onset da sílaba final. Uma vez que onsets nunca licenciam uma mora (HAYES, 1995), a circunscrição avança mais uma janela, parentetizando a margem esquerda da próxima sílaba, para efeitos confecção do molde.

Em segundo lugar, antropônimos como 'Mário'/'Maria', 'Márcio(a)' e 'Fúlvio' não se sujeitam à formação de hipocorísticos do tipo "A". No meu entender, a circunscrição não pode ser aplicada a esses dados exatamente pelo fato de eles apresentarem a mesma dimensão do molde (duas sílabas). Como vimos, nomes cujo tamanho coincida com o do molde formam hipocorísticos a partir de outras estratégias. A seqüência CiV (consoante-vogal alta-vogal) parece funcionar como uma única sílaba, aos olhos da circunscrição prosódica.

Por fim, seqüências formadas por obstruinte + líquida ou por obstruinte + vogal alta se comportam da mesma maneira na formação de hipocorísticos: o segundo elemento do grupo é sempre cancelado. Se interpretarmos a vogal alta anterior como membro de um onset complexo, é possível estender a condição (24b) aos dados apresentados em (25) e, com isso, admitir que a supressão de /i/ deriva de sua posição no interior da sílaba. Caso contrário, será extremamente difícil explicar por que a circunscrição prosódica (a) escaneia um trissílabo em 'Patrícia', mas não em 'Márcia' e (b) não isola um troqueu moraico em paroxítonos terminados em hiato ('Sofia' e 'Maria', entre outros). Por esses motivos, a seqüência -io(a) está sendo analisada como tautossilábica e o primeiro elemento, como membro de um onset complexo. Como hipocorísticos otimizam a posição de ataque, conservando sempre o elemento menos sonoro, o glide é cancelado pelas condições de boa-formação silábica, uma vez que onsets ramificados nunca são permitidos.

No que diz respeito à margem esquerda da sílaba, a situação é bastante diferente, uma vez que há relaxamento maior quanto à 
proibição de rimas ramificadas. Se, por um lado, alguns dados revelam supressão de codas (27, coluna 1), levando o hipocorístico a se constituir de sílabas com o formato CV, por outro, também há formas que mantêm a coda da circunscrição (coluna 2), preservando o padrão CVC das bases.

$$
\begin{array}{ll}
\text { Francisco }>\text { Chico } & \text { Fernando }>\text { Nando } \\
\text { Roberto }>\text { Beto } & \text { Reginaldo }>\text { Naldo } \\
\text { Eduardo }>\text { Dado } & \text { Rosimeire }>\text { Meire } \\
\text { Augusto }>\text { Guto } & \text { Leopoldo }>\text { Poldo }
\end{array}
$$

Como se vê, as formas de (27) indicam uma tendência a permitir sílabas travadas. Entretanto, essa tendência não é tão forte ou consistente como a de proibir sílabas sem onset ou a de simplificar ataques complexos. A líquida lateral (/l/), os glides (/y/ e /w/) e a nasal não-especificada para ponto de articulação (/N/) preenchem a posição de coda nos hipocorísticos, ao passo que a fricativa nãoespecificada para sonoridade (/S/) e a vibrante (/R/) são sempre deletadas. Desse modo, nem todos os segmentos licenciados para coda em português (COLLISCHONN, 2001) podem aparecer nos hipocorísticos.

Se uma condição de boa-formação do tipo "sílabas são sempre abertas" realmente fosse imperativa, não haveria razão para manter qualquer tipo de segmento em coda. Uma vez que existem sílabas fechadas nos hipocorísticos, podemos assumir que codas não são categoricamente barradas, mas condicionadas, de modo que sua presença é tolerada sob certas circunstâncias.

Mais uma vez, é possível recorrer ao Princípio de Sonoridade para explicar esse fato. Levando em conta que a sonoridade deve declinar minimamente na demissílaba final (CLEMENTS, 1990), rimas não podem ser constituídas de vogal + obstruinte, pois haveria declínio abrupto de sonoridade do núcleo para a coda (3-0), o que dá conta de 'Chico' e 'Guto' (hipocorísticos de 'Francisco' e 'Augusto', nesta ordem). ${ }^{10} \mathrm{O}$ problema que se coloca, quanto à utilização do 
Princípio de Seqüenciação de Sonoridade para explicar a manutenção/ supressão de codas nos hipocorísticos, é a proibição de "erre" no travamento de sílabas iniciais ('Roberto' > 'Béto') e a permissão desse mesmo segmento em sílabas finais ('Marimar' > 'Mar').

Nas últimas sílabas do prenome, a presença de uma consoante é decisiva para a formação de um troqueu moraico. Sendo assim, "erres" finais funcionam como unidades de peso, fazendo com que a circunscrição parentetize a sílaba da qual são codas. ${ }^{11}$ Na penúltima sílaba, entretanto, o peso já não tem qualquer efeito, o que favorece a supressão desse segmento.

Se interpretarmos que o "erre" pós-vocálico não se comporta como líquida, mas como fricativa ( $[\mathrm{x}, \gamma])$ que assimila o vozeamento do elemento seguinte (CRISTÓFARO SILVA, 1999), o Princípio de Sonoridade possibilita explicar o apagamento: a seqüência 3-0 (vogal-obstruinte) leva a um declive acentuado de sonoridade e, por isso, é simplificada nos hipocorísticos que admitem queda mínima de sonoridade na demissílaba final. Essa interpretação, no entanto, não dá conta das áreas dialetais em que o "erre" não se manifesta como fricativa, de modo que essa questão fica em aberto no momento.

\section{PALAVRAS FINAIS}

Enfatizei, ao longo do texto, que hipocorísticos equivalem a uma palavra mínima porque não podem apresentar mais de um pé binário. Quando a base excede esse limite, necessariamente haverá perda de massa fônica, resultando na preservação de apenas uma parte da palavra-matriz. A presença de estruturas não-marcadas resulta da demarcação de um troqueu moraico sobre a base e do papel das condições de boa-formação silábica sobre o molde, interpretado como mediador entre prenome e hipocorístico. As condições de boa-formação silábica atuam sobre o material escaneado para o molde e levam a um grau menor de identidade entre derivante e derivado, fazendo com que a Hipocorização se assemelhe à linguagem infantil. 
De acordo com GNANADESIKAN (1995), a aquisição da linguagem pode ser vista como um processo que promove a fidelidade à fala adulta, a partir de um estágio inicial em que a marcação é dominante, como se vê em (28). Nessa fase, condições que regulam estruturas não-marcadas são capazes de impedir que formas marcadas do output adulto sejam produzidas pela criança. Marcação, nesse ponto, reflete, nas palavras do autor, a babilidade rudimentar da criança para produzir contrastes sofisticados (p. 21). Uma vez que contrastes são necessários para suportar o léxico adulto, as condições de boa-formação silábica vão sendo progressivamente suplantadas por condições de fidelidade ao output adulto, que, como se vê no esquema abaixo, caracteriza-se por um balanceamento entre condições de marcação e condições de fidelidade, ranqueando-as alternadamente.

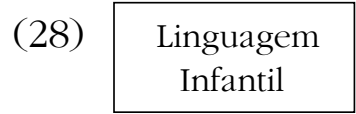

Marcação >> Fidelidade

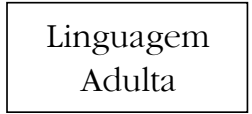

Marcação >> Fidelidade >> Marcação >> Fidelidade

Pelo que se expôs no decorrer deste trabalho, podemos afirmar que a hipocorização, sem dúvida alguma por seu caráter essencialmente afetivo, compartilha com estágios iniciais de aquisição ${ }^{12}$ essa tendência a ranquear marcação sobre fidelidade, fazendo superficializar formas menos complexas do ponto-de-vista prosódico, como sílabas CV e pés dissilábicos com cabeça à esquerda.

Cabe assinalar, no entanto, que as condições de fidelidade dominadas na hipocorização não são as mesmas dominadas na linguagem infantil. Enquanto formas não-marcadas da linguagem infantil resultam da dominância das condições de marcação sobre as de fidelidade entre um input (a fala do adulto) e um output (a fala da criança), as que caracterizam os hipocorísticos resultam de um ranqueamento similar, mas distinto, uma vez que as condições de fidelidade dominadas não são aquelas entre um input e um output, mas entre duas formas de output: o molde e o hipocorístico 
propriamente dito. Somente um modelo transderivacional, como o abaixo formalizado, pode dar conta do processo ora em análise.

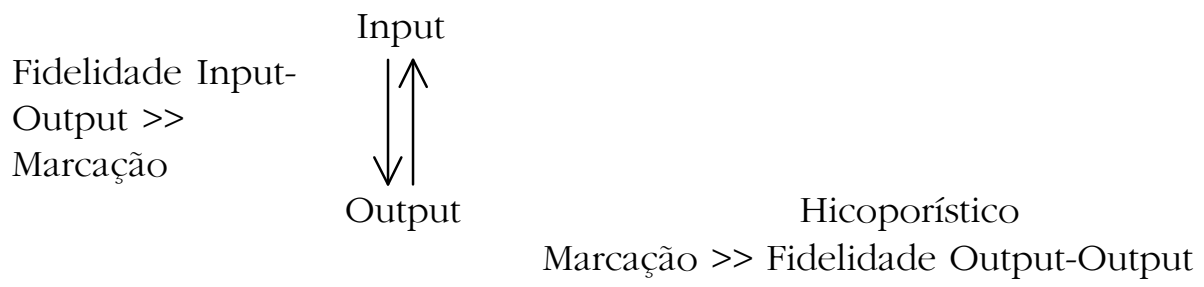

O modelo apresentado em (29) dá conta de um problema que poderia surgir numa análise unicamente derivacional do processo. Como mostrei na seção 4, hipocorísticos não podem converter vibrantes simples em múltiplas no pé trocaico que se forma pela circunscrição prosódica, em casos como 'Seve[rino]' $\rightarrow$ *[r]ino ou *[x]ino. Estratégias de reparo, qué garantem preservação à estrutura fonológica da língua, substituem o segmento inicial, copiando-se o onset da sílaba seguinte. Condições sobre o ataque dos hipocorísticos forçam diferenças entre eles e os moldes: esses casos constituem evidência empírica em favor de uma correspondência output-output (ou transderivacional), haja vista que hipocorísticos tendem a ser mais dependentes do molde que da própria palavra-matriz. Como a hipocorização reduz o prenome ao tamanho de uma palavra mínima, é o molde que, já subordinadas as condições de fidelidade, sofrerá os efeitos das condições de marcação.

Uma análise sobre o papel das restrições na emergência de hipocorísticos ótimos, portanto, dificilmente se sustentaria no paradigma da Teoria da Otimalidade Clássica (PRINCE \& SMOLENSKY, 1993). Como não há relação direta de identidade entre um inpute um output, a Teoria da Correspondência (MCCARTHY \& PRINCE, 1995 e BENUA, 1995) - que prevê atuação de um conjunto de restrições entre outputs - justifica-se como modelo paralelista mais adequado para lidar com fenômenos como o trabalhado. 


\section{NOTAS}

${ }^{1}$ Considero hipocorização somente o processo que altera a constituição fonológica de um nome próprio, seja a partir da diminuição de seu corpo fônico (cf. 'Nando', de 'Fernando'), seja por meio da reduplicação de uma seqüência (cf. 'Fafá', de 'Fátima'). Nas palavras de MONTEIRO (1987: 187), nomes afetivos que não resultam de variaçôes morfofonêmicas de um dado prenome ou sobrenome são apelidos (...), termo geral de que os hipocorísticos constituem espécie. Dessa forma, não interpreto como hipocorísticas formas como 'Tonca' e 'Totonho', de um lado, ou 'Quino' e 'Tico', de outro, consideradas apenas apelidos de 'Antônio' e 'Francisco', nesta ordem.

${ }^{2}$ De acordo com ARCHANGELI \& PULLEYBLANK (1994), subespecificação é o procedimento analítico relacionado à omissão de informações nas representações subjacentes, preenchidas mais tarde, a fim de se obter a representação de superfície.

${ }^{3}$ Outros processos tradicionalmente considerados marginais e "de difícil formalização" (SANDMANN, 1989), como o truncamento ('salafra', por 'salafrário'), o blend lexical ('gayroto', de 'garoto' + 'gay'), a reduplicação ('corre-corre', 'pegapega') e a siglagem ('CLA' - 'Centro de Letras e Artes'), também envolveriam atuação do chamado "morfema circunscritivo". Eles vêm sendo estudados por GONÇALVES (1999) e por GONÇALVES (em preparação), este último no âmbito da Teoria da Correspondência (McCARTHY \& PRINCE, 1995), uma extensão da Teoria da Otimalidade aplicada à Morfologia (BENUA, 1995).

${ }^{4}$ É possível dizer que o vocabulário do português requer condições de minimalidade. Excetuando-se os clíticos, apenas um pequeno contigente de palavras da língua não apresenta pelo menos um pé bimoraico, como, p. ex., 'fé', 'pá', 'pó', 'lá' e 'ló'. Sem dúvida alguma, a grande maioria dos monossílabos apresenta ramificação na rima.

${ }^{5}$ Em GONÇALVES (em preparação), está sendo desenvolvida uma análise dos hipocorísticos no âmbito da Teoria da Correspondência (McCARTHY \& PRINCE, 1995). Os tipos "B", "C" e "D" podem ser considerados variantes do tipo "A", emergindo como formas ótimas, somente quando esse último leva à criação de estruturas prosódicas marcadas, especialmente quando os inputs são prenomes acentuados na última sílaba leve ('Dedé', de 'André') ou na antepenúltima sílaba ('Gegé', de 'Angélica'), ou quando a sílaba proeminente da base não apresenta o onset ('Eduardo' e 'Leandro'), ou quando a sílaba final tem coda preenchida por elementos outros que não /l, r/ ('Carlos' e 'Vivian').

${ }^{6}$ Sob o rótulo "outros", aparecem tipos de hipocorização que não se enquadram em nenhum dos grupos apresentados. É o caso de 'Méia', de 'Salomé', e 'Deco', 
de 'André', que envolvem inserção de material fonológico após a tônica copiada. Além desses, dois outros também chamaram atenção: 'Ju', de 'Jussara' e 'Fá', de 'Fátima', hipocorísticos constituídos de uma única sílaba leve. Como esses monossílabos convivem com os dissílabos reduplicados ('Jujú' e 'Fafá'), é possível considerá-los encurtamentos dos hipocorísticos de tipo "C" e "D" e, por isso mesmo, reduções de uma palavra mínima. Outro tipo encontrado em português é o dos hipocorísticos iâmbicos ('Gabí', 'Manú', formados a partir dos antropônimos 'Gabriela' e 'Manoela', respectivamente), que, por não aparecerem na amostra, não serão comentados neste artigo. Também não analisarei hipocorísticos como 'Cadú', 'Malú' e 'Calê' (de 'Carlos Eduardo', 'Maria Lúcia' e 'Carlos Alexandre', nesta ordem). Formados a partir de nomes compostos, esses hipocorísticos envolvem blends lexicais e, por isso, não apresentam o mesmo comportamento dos demais.

${ }^{7}$ Hipocorizar significa fazer um encurtamento na palavra, de modo que esse processo, por definição, não pode preservar todos os segmentos da base. Dessa maneira, os elementos que estão fora do subdomínio criado serão sempre circunscritos negativamente.

${ }^{8}$ Como ressaltei na nota 6, formas como 'Jú' (de 'Juliana') e 'Dé' (de 'André') podem ser vistas como encurtamentos de palavras mínimas (dissílabos reduplicados). Uma vez que nem todos os hipocorísticos reduplicados apresentam monossílabos correspondentes (como 'Memé', de 'Salomé', que não forma *'Mé'), é possível afirmar que a formação de hipocorísticos monossilábicos é posterior à formação de reduplicados, o que não inviabiliza a hipótese de palavra mínima.

9 Apenas um hipocorístico apresentou sílaba sem onset - 'Edu'. Essa forma, no entanto, convive com duas outras ('Dado' e 'Dudu'), ambas com ataque preenchido, o que, por seu caráter marginal, não contraria a tendência de hipocorísticos banirem sílabas desprovidas de onset.

${ }^{10}$ Como a palatalização de /s/ não acontece em dados como 'Cida' ('Aparecida') e 'Cina' ('Alcina'), é possível admitir que esse processo é motivado não só pela presença da vogal alta anterior, mas também da fricativa em coda.

${ }^{11}$ É mais difícil determinar o status moraico do arquifonema /S/, pois os poucos antropônimos terminados em /S/ são paroxítonos (cf. 'Marcos' e 'Carlos'). Ao que tudo indica, esse segmento parece não contribuir para o peso da sílaba final, talvez por apresentar forma idêntica à do morfema de plural.

12 Também a chamada "lovers language", por ser marcada pela função expressiva, compartilha com a linguagem infantil e com a hipocorização essa tendência a privilegiar marcação sobre fidelidade. 


\section{REFERÊNCIAS BIBLIOGRÁFICAS}

ARCHANGELI, D.; PULLEYBLANK, D. Grounded Phonology. Cambridge/London: The MIT Press, 1994.

BENUA, L. Identify effects in morphological truncation. In: BECKMAN, J. (Ed.). Papers in Optimality Theory, 18 (1): 77-136, 1995.

BISOL, L. O ditongo na perspectiva da fonologia atual. DELTA, 5 (2): 185-224, 1989.

BISOL, L. O acento e o pé métrico. Letras de Hoje, 98 (1): 25-36, 1994.

BISOL, L. O troqueu silábico no sistema fonológico. DELTA, 16 (2): 403-13, 2000.

CABRÉ, T. Minimality in catalan truncation process. Catalan Working Papers in Linguistics, 4 (1): 1-21, 1994.

CLEMENTS, G. The role of sonority cicle in core syllabification. In: KINGSTON, J. \& BECKMAN, M. (Org.). Papers in Laboratory Phonology 1. Cambridge: CUP Press, p. 283-333, 1990.

COLINA, S. Spanish truncation processes: the emergency of the unmarked. Linguistics, 34 (1): 1199-218, 1996.

COLlisCHONN, G. A sílaba em português. In: BISOL, L. (Org.). Iniciação a estudos de fonologia do português brasileiro. 3. ed., Porto Alegre: EDUPUCRS, 2001.

CRISTÓFARO SILVA, T. Fonética e Fonologia do português. São Paulo: Contexto, 1999.

CUNHA, C. F. Nova gramática do português contemporâneo. Rio de Janeiro: Nova Fronteira, 1975.

DE LACY, P. Circumscriptive morphemes. In: KITTO, C. \& SWALLWOOD, C. (Ed.). Proceedings of the Sixty Meeting of the Austronesian Formal Linguistics Association. Holland: Hollan Academic Graphics, 1999.

FAUSTO, L. Ditongos crescentes no português do Rio de Janeiro: variação e distribuição lexical. Comunicação apresentada no VIII Congresso da Assel-Rio. Rio de Janeiro: UFRJ/Faculdade de Letras, p. mimeo, 1998.

GNANADESIKAN, A. M. Markedness and faithfulness constraints in child phonology. Rutgers Optimality Archive, 67-0000, 1995. 48 p.

GONÇALVES, C. Processos de redução vocabular em português: tipos de funções. Comunicação apresentada na XVII Jornada de Estudos Lingüísticos. Recife: UFPE, mimeo, 1999. 
GONÇALVES, C. (em preparação). Hipocorísticos e Otimalidade: restrições e emergência de formas ótimas. Campinas: UNICAMP/CNPq.

HAYES, B. Metrical stress theory: principles and case studies. Chicago: The University of Chicago Press, 1995.

JENSEN, J. Morphology: word structure in generative grammar. Cambridge: Cambridge University Press, 1991.

KIPARSKY, P. From cyclic phonology to lexical phonology. In: Der HULST, V. \& SMITH, N. (Ed.). The structure of phonological representation. Dordrecht: Foris Publications, 1982.

LEE, S. H. Fonologia e morfologia lexical do português. 1995. 181 f. Tese (Doutorado em Lingüística) - IEL. Unicamp, Campinas.

LEMLE, M. Heterogeneidade dialetal: um apelo à pesquisa. In: LOBATO, L. (Org.). Lingüística e ensino de vernáculo. Rio de Janeiro: Tempo Brasileiro, 1978, p. 60-94.

McCARTHY, J. A prosodic theory of nonconcatenative morphology. Linguistic Inquiry, 12 (3): 373-417, 1986.

McCARTHY, J. Lectures on Prosodic Morphology. Santa Cruz: LSA Summer Institute/ University of California at Santa Cruz, 1991.

McCARTHY, J.; PRINCE, A. Foot and word in prosodic Morphology. Natural language and Linguistic Theory, 8 (1): 209-84, 1990.

McCARTHY, J.; PRINCE, A. Generalized Alignment. In: BOOIJ, G. E. \& MARLE, J. (Ed.). Yerbook of Morphology. Dordrecht: Kluwer, 1993.

McCARTHY, J.; PRINCE, A. The emeergency of unmarked. Proceedings of NELS, 24 (1), 333-79, 1994.

MCCARTHY, J.; PRINCE, A. Faithfulness and reduplicative identity. Rutgers: Rutgers University, 1995.

McCARTHY, J.; PRINCE, A. Prosodic Morphology: constraint interaction and satisfaction. Amhert: University of Massachusets, 1996.

MASSINI-CAGLIARI, G. Cantigas de amigo: do ritmo poético ao lingüístico (...). 1995. 287 f. Tese (Doutorado em Lingüística) - IEL. Unicamp, Campinas.

MESTER, A. Patterns of truncation. Santa Cruz: University of California at Santa cruz, 1990.

MONTEIRO, J. L. Morfologia portuguesa. Campinas: Pontes, 1987. 
MONTEIRO, J. L. Dicionário de hipocorísticos. Disponibilidade e acesso: $<$ http://www.geocities.com.br/paris/cathedral/1036> (em preparação).

NESPOR, M.; VOGEL, I. Prosodic Phonology. Dordrecht: Foris Publications, 1986. PIÑEROS, C. E. Foot-sensitive word minimization in spanish. Revista Probus (no prelo).

PRINCE, A.; SMOLENSKY, P. Optimality Theory: constraint interaction in Generative Grammar. New Brunswick: University of Rutgers, 1993.

RUSSEL, K. Optimality and Morphology. In: ARCHANGELI, D. \& LANGEDOEN, D. T. (Ed.). Optimality Theory: an overview. Malden and Oxford: Blackwell, 1997.

SANDMANN, A. J. Morfologia Lexical. São Paulo: Contexto, 1989.

SPENCER, A. Morphological Theory. Cambridge: Basil Blackwell, 1991.

ZANOTTO, N. Estruturas mórficas do português. Caxias do Sul: EDUCRS, 1989. 